\title{
Motifs Leading to Philosophy of Life: A Study
}

\author{
Sanjay Chotaliya, \\ Assistant Professor, Government Arts College, Vallbhipur
}

\section{Introduction :}

Herman Hesse, who considered his role as a thinker "to leap and caper, to dream of what had never been thought of" is now numbered among the leading thinkers of the $20^{\text {th }}$ century. "A complex, subtle and allusive writer", as New York Times Book Review describes him, he is of equal shoulders to Thomas Mann and his contemporaries. 'The garden dwarf among the Nobel Prize winners', as Volker Michels (1977, p.5) describes him, Hesse with his 'Search for Self' in mostly all his works, added crowning glory with his sincere efforts in the world of philosophy.

Hesse is very well - known in fashioning his own inner experiences into a personal myth or metaphor enacted in and through language. His subjective fictions give account of life in its all colours with rich experiences of the world. There is no single sphere of life which had not been talked about by Hesse. His search for 'self - knowledge' may linger in readers' mind and spirit life long. His heroes, like an existential man, searching for meaning in the meaningless world, refuse to be average men who consolidate the existing form of a race, a species and a way of life but choose their own way. Hesse is a lover, observer and participant of life who has enriched, varied and diversified fields of knowledge by exploring his first handed experiences with the depth of his scholarship. The Saturday review of New York Times has observed, "No other German writer has spoken out about life as passionately as Hesse . . . An existential intensity and a depth of understanding that are rare in contemporary fiction". This makes him an existential thinker

A literary figure speaks through his characters and the events they are involved. In Hesse's ideas on life and learning are ingrained in what the heroes do in his novels. The study has revealed that there are some motifs which are repeatedly interwoven in the plots his novel. This sort of repetition, indicative of the author's emphasis on certain ideas and ways of living life, exert indirect but definite effect on the conception of the act of education. Motifs are the repetitions contributing to build up Hesse's philosophy of life. Hence, both of these: motifs and his views on life have been derived here and elaborated as inputs .

\section{Motifs in Hesse's Novels}

A motif is a recurring fragment, theme or pattern in a creative work. Hesse's novels show some themes and patterns which speak of his latent philosophy. Presented here are the motifs used by Hesse in his novels.

\section{(1) Discontent:}

Discontent is a state of mind in which a person may appear happy but inwardly he becomes restless. Coupled with unhappiness, it brings uneasiness, frustration and annoyance. Hesse's characters reject the secure stage of their life due to the discontent they feel. Siddhartha was not happy with the ways of Brahmins to attain moksha. Harry feels irritation for the bourgoise culture. Sinclair is uneasy about his family security. Goldmund expresses his discontent with the monastic way of living whereas Knecht feels discontent of the artificial life of Castalia. This makes all of them break away from the way they were living and set on a journey of self search. Through this motif Hesse wants to project that discontent ignites self search.

\section{(2) Raising Questions to Self and Others :}

Dissatisfied with the present state, the protagonists approach someone else or try to ask questions to themselves. Hesse's heroes Siddhartha and Harry are shown questioning others and also to their selves. Siddhartha can be called a novel of questions. He asks a series of questions. e.g. why must he (Brahmin)...wash away his sins? Is Atman not within? Goldmund seems asking many questions to himself while living as a wanderer. Knecht and Sinclair find the Music-Master, and Demian as well as Eva for their questions. Their questions are answered either by their intuition, reflection or an authority. Hesse wants to communicate that in such a state of mind, a person enters into dialogue with the self and others which gives a temporary relief to their discontent or compels the hero for further reflection. 
(3) Break with Something :

The novels under study depict break with something. Demian explores break with conventional morality in a decaying world. Siddhartha projects break from religious, social and emotional bondages. Steppenwolf attains a complete break with the past. Glass Bead Game projects break with a system and Narcissus and Goldmund pictures a break with sensuous passions. 'Breaking with something', being the major focus of his novels, Hesse puts his heroes in acts like feeling discontent, inquiring, reflecting, doubting, awakening, participating in situations, falling in love, discarding worldly affection and feeling oneness with all.

\section{(4) Reflecting :}

Reflection is a state of mind a person enters into, after / while passing through experiences. It includes close examination of one's past acts, thinking over their consequences and observing the self. All Hesse's heroes get immersed in situations and reflect over them. This process enables them to take ethical judgements, decide future course of life and refine their senses. Hesse wants to project that experiencing in itself is not educative, reflecting over what is experienced, what is felt is needed to unlearn the previous inane, associative learnings.

\section{(5) Mentor-Mentee Relationship}

The notion of mentor - mentee relationship is central in Siddhartha, Demian and Glass Bead Game. Siddhartha accepts Vasudeva as his mentor - Sinclair accepts Demian, pistorius and in the end, Eva. The Music Master in Glass Bead Game acts as a mentor to Knecht. For Hesse, self discovery is not as passive as sitting in a room alone and contemplating. Rather, it can be an interactive task wherein one person helps another. Infact, the mentoring relationship are valuable to heroes not only because they lead them to change their world - view, but also for the friendship and kinship they produce. Through such relationship Hesse's heroes feel strongest emotions which otherwise may not be possible.

\section{(6) Seeking Help from Female Characters :}

Throughout the stages of their lives, Hesse's heroes turn to many women and learning new things. Kamala, Hermine, Maria, Eva, Lydia become instrumental in making the heroes realize the inevitable force of the drives and refinement of senses. Hesse has portrayed all these women more as symbols rather than persons. They shape protagonists' view of holistic reality. They are the female part - anima - of these heroes and therefore they compensate for the deficit in learning.

\section{(7) Awakening :}

Awakening is moment of revelation in which character is suddenly overwhelmed by a flash of insight into his life. Siddhartha, Goldmund and Knecht are shown experiencing awakening. In many cases these happens two or three times too! Hesse wants to project that such events bring a turn in heroes' lives without pushing them into guilt - conscience.

\section{(8) Experiencing Polarity / Dilemma :}

The inner conflicts of the heroes related to ethical issues are projected by the experience of polarity. Siddhartha experiences the polarity of good and evil. Sinclair experiences the duality of the dark world and the world of light. Harry experiences the polarity of intellectuality and sensuality. Knecht experiences the polarity of Castalia and the real world. Goldmund experiences duality of human nature. His heroes undergo first hand experience of the poles and finally realize the unity of all. Hesse believes that polarity exists only when one views a dilemma with reference of time. If one starts living in present, he believes in 'life of here and now' where no duality persists.

\section{(9) Call from Nature :}

Nature plays a vital role in Hesse's novels. Siddhartha wanders and learns a lot from the river. Goldmund too experiences nature in its vivid forms. Caught-up in a rigid system, Knecht dreams of his wandering in woods. He learns a lot from Bamboo grove. Hesse opines that his heroes respond to the call from nature. Nature becomes an instrumental in experiencing unity of all.

\section{(10) Homelessness :}

In the beginning of the novels, Hesse's heroes are shown enjoying the security offered by their homes. Then in search of identity, they renounce their parental homes and prefer homelessness. Siddhartha and Goldmund live life of wanderers. Harry's self integrity is made possible not in his bourgeois home. Sinclair lives in a boarding school and begins his self search. Knecht has no knowledge of his parental roots and lives in an organization. The homelessness provides novel experiences to the heroes. In case of Siddhartha, Goldmund 
and Sinclair, going out of the home was their own choice leading to infinite freedom. Hesse wants to suggest that homely security brings with it impositions and ideals which obstruct freedom.

\section{(11)Self Abuse :}

Hesse's heroes exercise their freedom of choice and bear the consequences. They experience deep ennui, misery and feel that there is nothing left in the world that could attract or give pleasure or solace. This is experienced by Siddhartha ( $p, 87-88$ ). He abuses himself on realizing a worthless life of the world. Goldmund also feels the same on his life as a wanderer. His inner emptiness causes self abuse. Harry, failing to reconcile his two contradictory selves, abuses himself. Hesse tells that on a journey of self realization, one is expected to check constantly on his actions. Realisation of follies, one has committed, disturbs one but evidently proves the past as absurd. Self abuse thrives on reflection on the self but ultimately imparts better understanding of the self.

\section{Hesse's Philosophy of life}

Hesse attempts to explore the question - what shall we do with our lives? In all his novels his heroes are shown conducting 'experiments in living' (Colins, p.51, 1995). For each of his heroes life is a personal odyssey characterized by dissatisfaction with the set rules and traditions, an awareness of the present state of dependence, readiness to meet the challenges by choosing an unprescribed path, listening to one's inner being, rejection of the set system and construction of a system of one's own. Their involvement with the situations transforms them from mere 'individuals' to 'persons.' Hesse allows his heroes to learn by discarding their perspectives until all mental blocks vanish. Hesse's philosophy of life, derived from the study of his five novels, covers vast spectrum of life and living. His philosophy of life can be explained under following heads.

\section{(1)Concept of Life}

For Hesse, life is a journey of the self. Man's participation into series of situations is the prerequisite for this. It is centered on unlearning - learning and experiencing.

Hesse submits that life cannot be planned. At the spur of the moment, one has to choose unprescribed, risky path accepting the life as it unfolds. If life is planned, it would not let any one enjoy living. Planning brings with it worries of outcomes and unnecessary expectations. A spontaneous life widens space for freedom and choice.

\section{- Unlearning Learning}

Hesse questions the permanence of any learning. Something learnt in one situation needs to be unlearnt in the subsequent situation. The chain of unlearning - learning indicates one's development wherein one keeps on unlearning what is useless or unnecessary. He does not say that previous experiences go in vain. $\mathrm{He}$ just points out that previous learning may be beneficial to subsequent learning. But one should be flexible enough to unlearn past learning. Thus, for Hesse, life is : "project unlearning learning."

- Experiencing chaos

According to Hesse, in life one cannot escape chaos by refusing it. Plunging into it is a must. The first hand experience of chaos develops new wisdom. This enables one to realize that life is a mixture of good and evil. It is only after participation in situation; one can take judgement of what is good and what is evil.

\section{(2)Aim of Life}

The aim of life according to Hesse is refinement of senses until depassioning and debecoming take place. A person normally intends to be in the world of innocence, living a secure life. Those having higher goal step towards world of knowledge and wisdom. Intellectuality often brings barriers in allowing one be in the situation. Hesse opines that participation in emotion driven acts brings balance between intellectuality and passion. This is how education of senses takes place.

\section{(3) Values of Life}

Hesse is against the adherence to set values. A person is always in making and is a creator of his own values. The life values he proposes are doubting the tradition, venturing, exercising freedom, choosing own path, bearing consequences of acts, mobility and love. An authentic life demands breaking from a system or no following of others. Crossing the given boundaries is the foundation of Hesse's views on values of life.

\section{(4)Reality of Life:}

For Hesse, reality of life is a series of situations. The course of life consists of passing through new experiences, reflecting over the self and situation and choose the future course of life. If a person just lets himself flow, he is likely to commit mistakes. Experiences expand perspectives and impart new knowledge. Plunging into series of situations doesn't create worry for the consequences or any expectations. The main task 
of life is 'orientation to the world', through which man enables himself to deal with the world and obtain phenomenal knowledge.

\section{(5)Place of Emotion in Life}

For Hesse life is lived through emotions, not through intellect. Powerful feelings and reflection over them impart finer and mature discrimination. This ultimately leads to self knowledge.

\section{(6)Place of others in Life}

For Hesse, 'others' are social reality who try to impose the set traditions, values and ideals on a person. These others obstruct free thinking and risk-taking of a person. Man determined to venture the risky path of life rejects such others who oppress him. Hesse also projects that among such oppressive others, there are few who facilitate the venturing individual. They provide experiences to the person enter into relations and try to compensate what is lacking. Hesse points out that life's road is smoothened by such relationships. Such relations develop a capacity in an individual to discard otherness and be one with all. Intersubjectivity is the path and witnessing the others is a status.

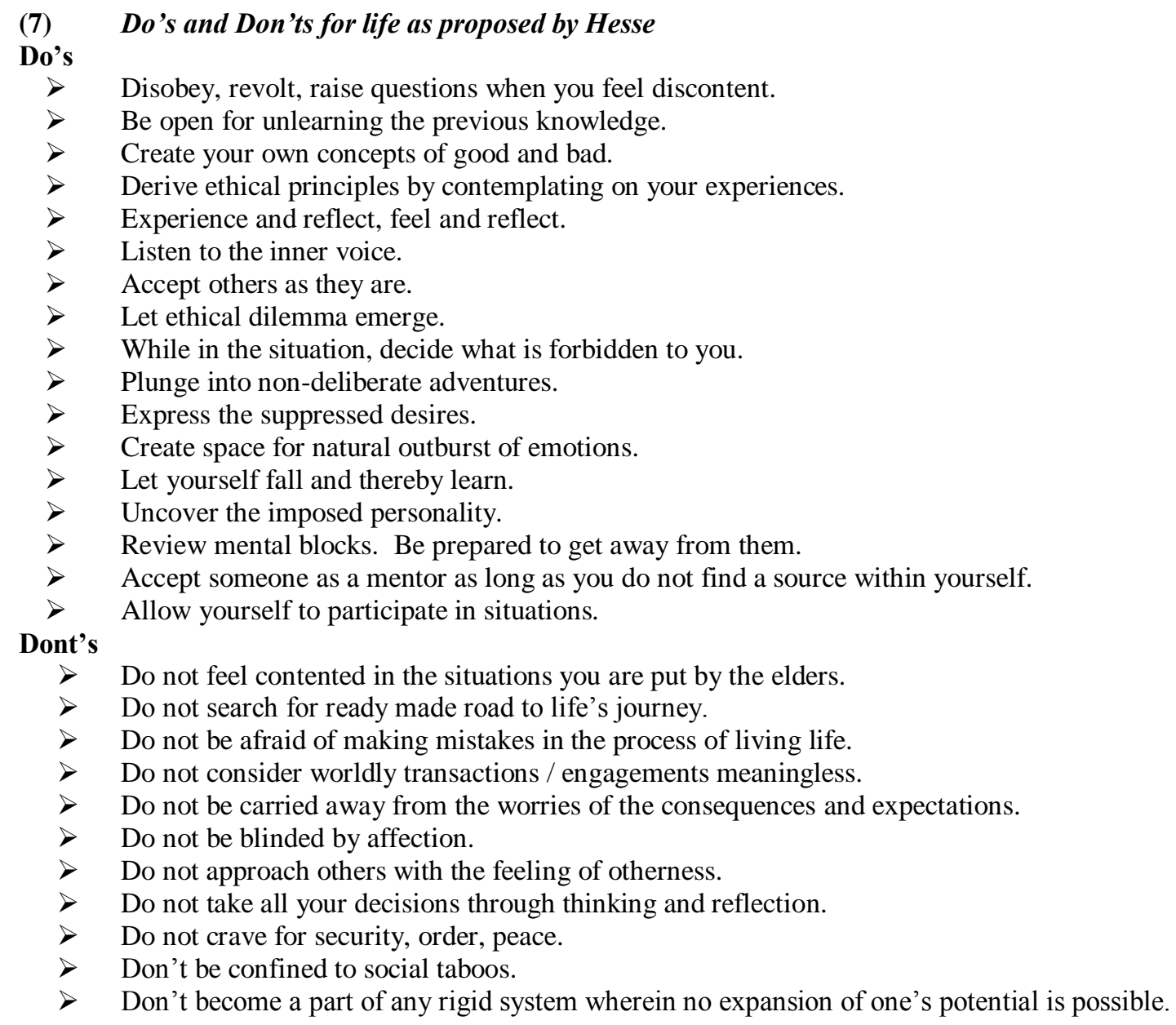

\section{Conclusion:}

Aristotle perhaps didn't go far enough when he said that tragedy was more philosophic than history, concentrating as it does on what might be rather than merely on what had been. He might have gone on to say that tragedy — or, more broadly, literature - is more philosophic even than philosophy. It is a form of knowledge that draws on all our ways of knowing, rather than on ratiocination alone. And it is a more intense form of knowledge, since, unlike philosophy, it isn't constantly taking its own pulse, or checking its instruments, anxiously asking itself how it can know this or that. As Dickens would say, it just goes and knows it. Two or three decades ago, the belief that literature was a repository of knowledge - and important knowledge - was usual enough for critics to take it for granted. At the very least, everybody understood that literature was a storehouse of documentary knowledge. We could learn about how others lived-the Greeks, the men of the Middle Ages, our own contemporaries: how they judged one another, what they considered good manners, how 
they fell in love, what their family life was like, how they structured their society, when they dined, how they grew up and took their place in the world of adults. But that was only the beginning. Literature also teaches us more about psychology than the psychologists can. The inner life - and its relation to the outer appearance, from which it is often (and proverbially) very different-is literature's special subject. It is a particularly complex subject, with it's interweaving of motives and impulses, as appetites grapple with ideals, as consciousness both registers and distorts external reality, as natural promptings intersect with social ambitions, and the universal in our nature takes on the fashion and the garb of a particular age. These ideas find its expression in the analysis of motifs and philosophy of life of Hesse's Major novels.

\section{References:}

[1]. Boulby, Mark. (1967). Hermann Hesse : His Mind and His Art. New York. Cornell University Press.

[2]. Durrani, Osman. (1994). Fiction of Germany : Images of German Nation in the Modern Novel. Edinburgh. Edinburgh University Press.

[3]. Kenocian. (1995). Studies on Themes and Motifs in Literature. New York. Peterland Publishing Inc.

[4]. Richards, David. (1996). Exploring the Divided Self. Camden. Camden House.

[5]. Stelzig, Eugen .(1988). Fictions of the Self. Princeton. Princeton University Press.

[6]. Smith, T.D. (1997). A Three-stage Process of Humanization Depicted in the Novels of Hermann Hesse. University of Baffalo. Department of Modern Languages and Tileralurs. Ph.D.

[7]. Ziolkowski, T. (1965). The Novels of Hermann Hesse : A Study in Theme and Structure. Princeton. Princeton University Press. 